\title{
Outcome of short-term systemic steroid therapy in chronic obstructive pulmonary disease patients with acute exacerbation
} Ashraf Zin El-Abdeen ${ }^{a}$, Lamiaa H. Shaaban ${ }^{a}$, Shereen Farghaly ${ }^{a}$, Hanan Galal ${ }^{b}$, Entsar H. Mohammed ${ }^{a}$

\begin{abstract}
Background There are insufficient data on the optimum duration of systemic steroid therapy during acute exacerbation of chronic obstructive pulmonary disease (COPD).
\end{abstract}

Aim To evaluate the outcome of short-term systemic steroid therapy in patients hospitalized with acute exacerbation of COPD and to identify factors associated with treatment failure.

Patients and methods Fifty severe and very severe COPD patients with acute exacerbation were consecutively included in this study. Patients were assessed by a clinical symptom score, peak expiratory flow rate (PEFR), arterial blood gases and laboratory investigations [blood count indices, high sensitive C-reactive protein, erythrocyte sedimentation rate (ESR) and fibrinogen level]. Short-term systemic steroids were initiated and the outcome was assessed at day 5 of therapy and the patients were classified into treatment success group or failure group.

Results Treatment failure was observed in 27 (54\%) of patients. Patients with treatment failure had significantly higher cough and chest tightness scores, higher partial pressure of $\mathrm{CO}_{2}$ in arterial blood $\left(\mathrm{PaCO}_{2}\right)$, lower partial pressure of $\mathrm{O}_{2}$ in arterial blood $\left(\mathrm{PaO}_{2}\right)$, lower PEFR, higher red distribution width (RDW), and higher ESR compared with the success group. By binary logistic regression, higher

\section{Introduction}

Chronic obstructive pulmonary disease (COPD) is a common preventable and treatable disease, characterized by airflow limitation and persistent respiratory symptoms that is usually progressive and is associated with an enhanced chronic inflammatory response in the airways to noxious particles or gases [1]. During the course of the disease, periods of exacerbations or flares up may occur [2]. During exacerbations, inflammatory markers such as tumor necrosis factor- $\alpha[3,4]$ and inflammatory cells such as neutrophils [5], eosinophils [6], and cluster of differentiation 4 (CD4) cells [7] are collected in the respiratory system causing local inflammation. The markers of systemic inflammation also increase. The fibrinogen level is increased when purulent sputum is observed during exacerbations [8]. The $\mathrm{C}$-reactive protein $(\mathrm{CRP})$ levels are also increased in bacterial acute exacerbation of chronic obstructive pulmonary disease (AECOPD) [9].

There were strong evidence that systemic corticosteroids in COPD exacerbations improve FEV1, arterial hypoxemia, decrease hospital stay, and
$\mathrm{PaCO}_{2}$, lower $\mathrm{PaO}_{2}$, and higher ESR were independent risk factors associated with treatment failure. The optimum cutoff level of $\mathrm{PaCO}_{2}, \mathrm{PaO}_{2}$, and PEFR associated with treatment failure was more than or equal to $59.5 \mathrm{mmHg}$, up to 43.5 $\mathrm{mmHg}$, and up to $225 \mathrm{l} / \mathrm{min}$, respectively. ESR first hour of at least 35 and RDW of at least $15.5 \%$ were also associated with treatment failure.

Conclusion Most severe and very severe COPD during acute exacerbations need prolonged course of systemic steroids ( $>5$ days). Clinical evaluation, gasometric parameters, PEFR, RDW, and ESR could be good predictors of treatment failure on short-term systemic steroid. Egypt J Bronchol 2018 12:310-316 (C) 2018 Egyptian Journal of Bronchology

Egyptian Journal of Bronchology 2018 12:310-316

Keywords: acute exacerbation of chronic obstructive pulmonary disease, chronic obstructive pulmonary disease, short-term systemic steroid

Departments of, ${ }^{a}$ Chest, ${ }^{b}$ Clinical Pathology and Immunology, Faculty of Medicine, Assiut University Hospital, Asyut, Egypt

Correspondence to Shereen Farghaly, MD, Department of Chest, Faculty of Medicine, Assiut University Hospital, Asyut 7111, Egypt

Tel: +20 1096429078

e-mail: shereen_hssn@yahoo.com

Received 7 October 2017 Accepted 6 December 2017

decrease the incidence of treatment failure. Oral prednisolone at a dose of $30-40 \mathrm{mg}$ (or equivalent) is preferred as daily therapy during exacerbations [1]. However, there are insufficient data concerning the optimum duration of systemic steroid therapy during COPD flare-up.

\section{Aim \\ To evaluate the outcome of short-term systemic steroid therapy ( $\leq 5$ days) in COPD patients hospitalized with acute exacerbation and to identify factors associated with treatment failure.}

\section{Patients and methods}

This prospective study was carried out in the Department of Chest Diseases, Faculty of Medicine, Assiut University

This is an open access journal, and articles are distributed under the terms of the Creative Commons Attribution-NonCommercial-ShareAlike 4.0 License, which allows others to remix, tweak, and build upon the work non-commercially, as long as appropriate credit is given and the new creations are licensed under the identical terms. 
Hospital during the period from October 2015 to October 2016. COPD patients hospitalized with acute exacerbation were consecutively enrolled in this study. The study was approved by the Faculty of Medicine Ethics Committee, Assiut University.

\section{Study design}

Fifty COPD patients [diagnosed by spirometry (FEV1/FVC $<70 \%$ within 6 months)] [1] hospitalized with acute exacerbation were consecutively enrolled in this study. Anthonisen's Winnipeg criteria [10] were used to define COPD exacerbation into either type I, type II, or type III. All patients received short-term steroid (40 $\mathrm{mg}$ prednisolone or equivalents for 5 days) [11], controlled oxygen therapy, inhaled B2 agonist, ipratropium bromide, and systemic antibiotics [12].

\section{Exclusion criteria}

(1) COPD overlapped with either bronchial asthma, interstitial lung diseases, and obstructive sleep apnea syndrome.

(2) COPD associated with pneumonia.

(3) COPD patients in whom systemic corticosteroids were contraindicated.

(4) COPD patients who used home systemic steroids in the last 4 weeks before admission.

\section{Assessment of the study group}

COPD patients underwent clinical, gasometric, functional, bacteriological, and laboratory assessment.

\section{Clinical assessment}

Data on demographic variables (age of the patient, sex, smoking history) and the presence of cor-pulmonale or comorbidities such as diabetes mellitus and hypertension were recorded on admission to hospital.

Clinical assessment score was used to assess COPD exacerbation severity [13]. It includes four symptom scores: shortness of breath score, cough score, chest tightness score, and the nighttime awaking score. Each of which takes a score according to the severity grading from 0 to 4 . The total score was calculated as the sum of all scores and equals 16 . With a score of 16 being the worst and a score of 0 being the best. Each symptom score and the total score were recorded at day 1 and 5 after initiation of treatment [13].

\section{Gasometric assessment}

ABGs were obtained at room air using heparinized blood sample and were analyzed using blood gas analyzers (Rapid lab850; CHIRON/Diagnostics; critical care systems, Medfield, MA, USA).

\section{Functional assessment}

PEFR (Using Clement Clarke International the MiniWright Peak Flow Meter) was applied for monitoring of patients' pulmonary function at day 1 and 5 of the study period.

\section{Bacteriological assessment}

Sputum samples were collected early in the morning in sterile containers and sent to the laboratory. Samples were then cultured using blood agar to show the characteristic colonies. Then identification was made by various serological or biochemical tests. According to sputum culture, the patients were classified into: class A; class B, and class C [14].

\section{Laboratory assessment}

For evaluation and monitoring of systemic inflammation during exacerbation, laboratory investigations including blood count indices, high sensitive $\mathrm{CRP}$, erythrocyte sedimentation rate (ESR), and fibrinogen level were collected at day 1 and day 5 of the study period. All venous samples were processed from 1 to $6 \mathrm{~h}$. For the evaluation of blood indices, $2 \mathrm{ml}$ of venous blood was placed in standard tubes containing K3 EDTA. The samples were processed within $1 \mathrm{~h}$ to minimize bias variation due to possible sample aging. ESR were measured using the Westergren method where the rate of sedimentation of RBCs in a column of blood was recorded at the first hour and second hour. Using the CardioPhase high sensitivity CRP device, $3 \mathrm{ml}$ of venous blood was put in a serum separator tube containing polystyene particles coated with monoclonal antibodies specific to human CRP. These particles when mixed with the samples aggregated and emitted a beam of light in proportion to the concentration of the CRP in the sample. Serum fibrinogen levels were also detected using the electromagnetic mechanical clot detection/radial immunodiffusion method.

\section{Outcome assessment}

At day 5 of treatment of AECOPD, treatment failure was defined by the presence of anyone of the following: persistence or deterioration of symptoms, appearance of new symptoms, need for noninvasive ventilation, ICU admission, or occurrence of death [15].

\section{Statistical analysis}

Statistical package for the social sciences (SPSS) program, version 20 for Windows was used for statistical analysis of the results in this study. Data were analyzed by nonparametric tests. The predictors of short-term systemic steroid therapy failure in AECOPD was done using binary logistic regression. 
Results will be considered significant with a $P$ value of less than 0.05. Receiver operating characteristic curve was applied to determine the optimum cutoff level of gasometric, functional, and laboratory parameters associated with treatment failure.

\section{Results}

This study included 50 severe and very severe COPD patients hospitalized with acute exacerbation. Sixtyfour percent of the included patients were men, with a mean age of $60.96 \pm 9.08$ and $14 \%$ of them were current smokers. According to response to systemic steroids, 27 (54\%) of the patients were classified as the treatment failure group and $23(46 \%)$ as the treatment success group. Demographic and clinical data of the two groups are presented in Table 1 . There was no significant difference between treatment failure and success groups as regards age, sex, GOLD stage, sputum culture, and type of exacerbation.

On univariate analysis between the two groups, patients with treatment failure were significantly presented with higher cough and chest tightness scores compared with the treatment success group ( $3.1 \pm 0.7$ vs. $2.6 \pm 0.7, P=0.012 ; 2.9 \pm 0.6$ vs. $2.5 \pm 0.2$, $P=0.003$, respectively). They had a significantly higher partial pressure of $\mathrm{CO}_{2}$ in the arterial blood

Table 1 Demographic and clinical data of treatment failure and treatment success groups among chronic obstructive pulmonary disease patients

\begin{tabular}{|c|c|c|c|}
\hline & Treatment failure group $(n=27)[n(\%)]$ & Treatment success group $(n=23)[n(\%)]$ & $P$-value \\
\hline Age (mean $\pm S D)$ (years) & $62 \pm 8.2$ & $59 \pm 9.8$ & 0.771 \\
\hline \multicolumn{4}{|l|}{ Sex } \\
\hline Female & $9(33)$ & $9(39)$ & 0.440 \\
\hline Male & $18(66)$ & $14(60)$ & 0.448 \\
\hline \multicolumn{4}{|l|}{ Gold stage } \\
\hline III & $10(37)$ & $8(34)$ & 0.670 \\
\hline IV & $17(62)$ & $18(78)$ & 0.771 \\
\hline \multicolumn{4}{|l|}{ Sputum culture } \\
\hline Class A & $9(33)$ & $14(60)$ & 0.356 \\
\hline Class B & $12(44)$ & $8(34)$ & 0.304 \\
\hline Class C & $6(22)$ & $1(4)$ & 0.312 \\
\hline \multicolumn{4}{|l|}{ Winnipeg score } \\
\hline Level I & $10(37)$ & $8(34)$ & 0.584 \\
\hline Level II & $14(51)$ & $10(43)$ & 0.583 \\
\hline Level III & $3(11)$ & $5(21)$ & 0.521 \\
\hline \multicolumn{4}{|l|}{ Comorbidities } \\
\hline $\mathrm{DM}$ & $22(81)$ & $14(60)$ & 0.126 \\
\hline HTN & $10(37)$ & $7(30)$ & 0.767 \\
\hline Cor-pulmonale & $21(77)$ & $12(52)$ & 0.076 \\
\hline IHD & $4(14)$ & $1(4)$ & 0.357 \\
\hline
\end{tabular}

DM, diabetes mellitus; HTN, hypertension; IHD, ischemic heart disease.

Table 2 Baseline clinical, gasometric, and functional parameters of treatment failure and treatment success groups among chronic obstructive pulmonary disease patients

\begin{tabular}{|c|c|c|c|}
\hline & Treatment failure group $(n=27)($ mean $\pm S D)$ & Treatment success group $(n=23)($ mean \pm SD $)$ & $P$-value \\
\hline \multicolumn{4}{|l|}{ Clinical symptom score } \\
\hline Shortness of breath score & $3.3 \pm 0.6$ & $3.4 \pm 0.5$ & 0.452 \\
\hline Cough score & $3.1 \pm 0.7$ & $2.6 \pm 0.7$ & $0.012^{*}$ \\
\hline Chest tightness score & $2.9 \pm 0.6$ & $2.5 \pm 0.2$ & $0.003^{*}$ \\
\hline Nighttime awaking score & $2.9 \pm 0.6$ & $2.5 \pm 0.8$ & 0.099 \\
\hline Total score & $11.9 \pm 2.1$ & $11.5 \pm 1.9$ & 0.430 \\
\hline \multicolumn{4}{|l|}{ Gasometric parameters } \\
\hline $\mathrm{pH}$ & $7.35 \pm 0.05$ & $7.38 \pm 0.08$ & $0.038^{*}$ \\
\hline $\mathrm{PaCO}_{2}(\mathrm{mmHg})$ & $67 \pm 11.3$ & $52 \pm 15$ & $0.002^{*}$ \\
\hline $\mathrm{PaO}_{2}(\mathrm{mmHg})$ & $39 \pm 5.2$ & $49 \pm 12$ & $0.001^{*}$ \\
\hline $\mathrm{SaO}_{2}(\%)$ & $72 \pm 7.1$ & $80 \pm 12.4$ & $0.005^{\star}$ \\
\hline $\begin{array}{l}\text { Functional parameters } \\
\text { (PEFR) (I/min) }\end{array}$ & $228 \pm 69$ & $269 \pm 69$ & $0.028^{*}$ \\
\hline
\end{tabular}

$\mathrm{PaCO}_{2}$, partial pressure of $\mathrm{CO}_{2}$ in arterial blood; $\mathrm{PaO}_{2}$, partial pressure of $\mathrm{O}_{2}$ in arterial blood; PEFR, peak expiratory flow rate; SaO , oxygen saturation in the arterial blood; *Significant. 
$\left(\mathrm{PaCO}_{2}\right)$, but lower partial pressure of $\mathrm{O}_{2}$ in the arterial blood $\left(\mathrm{PaO}_{2}\right)$ compared with the success group $(67 \pm 11.3$ vs. $52 \pm 15, P=0.002 ; 39 \pm 5.2$ vs. $49 \pm 12, \quad P=0.001$, respectively). Functionally, the treatment failure group had significantly lower PEFR compared with the success group (228 \pm 69 vs. $269 \pm 69, P=0.028$ ) (Table 2). Regarding laboratory parameters, red distribution width (RDW), ESR first, and ESR second hours were significantly higher in the treatment failure group compared with the success group $(17.8 \pm 4.1$ vs. $15 \pm 4, P=0.021$; $40.6 \pm 20$ vs. $28.6 \pm 15.6, \quad P=0.036 ; \quad 55.7 \pm 21.9$ vs. 41.9 $\pm 19.1, \quad P=0.016) \quad($ Table 3). Also baseline $\mathrm{CRP}$ and fibrinogen levels were higher in the treatment failure than the treatment success group, but the result does not reach significance difference.

However by binary logistic regression, higher $\mathrm{PaCO}_{2}$, lower $\mathrm{PaO}_{2}$, and higher ESR were independent risk factors associated with treatment failure with short-term steroid therapy in AECOPD (Table 4).

Receiver operating characteristic curve was done to evaluate the optimum cutoff level of gasometric, functional, and laboratory parameters associated with treatment failure. The optimum cutoff level of
$\mathrm{PaCO}_{2}$ associated with treatment failure was at least $59.5 \mathrm{mmHg}$ with a sensitivity of $77.8 \%$ and specificity of $66.2 \%$ as shown in Fig. 1a. $\mathrm{A} \mathrm{PaO}_{2}$ of up to $43.5 \mathrm{mmHg}$ was associated with treatment failure with a sensitivity of $81.5 \%$ and specificity of $69.6 \%$ (Fig. 1b). A PEFR of up to $2251 / \mathrm{min}$ was associated with treatment failure with a sensitivity of $74.1 \%$ and specificity of $69.6 \%$ (Fig. 2). ESR first hour of at least 35 was associated with treatment failure with a sensitivity of $55.6 \%$ and specificity of $74.9 \%$ (Fig. 3a). An

\section{Figure 1}

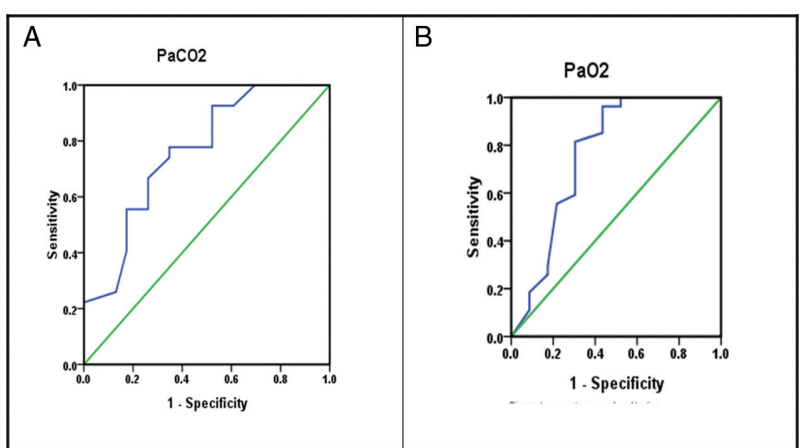

ROC curve of optimal cut-off level of $\mathrm{PaCO}_{2}(\geq 59.5)$ associated with treatment failure with sensitivity of $77.8 \%$ and specificity of $66.2 \%$ (figure A). ROC curve of optimal cut-off level of $\mathrm{PaO}_{2}(\leq 43.5)$ associated with treatment failure with sensitivity of $81.5 \%$ and specificity of $69.6 \%$ (figure B).

Table 3 Baseline laboratory parameters of treatment failure and treatment success group among chronic obstructive pulmonary disease patients

\begin{tabular}{lccc}
\hline & Treatment failure $n=27($ mean \pm SD) & Treatment success $n=23($ mean \pm SD $)$ & $P$-value \\
\hline WBCs $\left(\times 10^{3} / \mu \mathrm{l}\right)$ & $13 \pm 5.7$ & $12.1 \pm 4$ & 0.533 \\
Eosinophil $\left(\times 10^{3} / \mu \mathrm{l}\right)$ & $0.59 \pm 0.4$ & $0.33 \pm 0.46$ & 0.143 \\
Platelet $\left(\times 10^{3} / \mu \mathrm{l}\right)$ & $272 \pm 121$ & $247.8 \pm 85$ & 0.704 \\
MPV $(\mathrm{Fl})$ & $9 \pm 2.3$ & $9.5 \pm 2.5$ & 0.544 \\
RDW $(\%)$ & $17.8 \pm 4.1$ & $15 \pm 4$ & $0.021^{*}$ \\
Basophils $\left(\times 10^{3} / \mu \mathrm{l}\right)$ & $0.13 \pm 0.12$ & $0.16 \pm 0.15$ & 0.422 \\
ESR first hour $(\mathrm{mm} / \mathrm{h})$ & $40.6 \pm 20$ & $28.6 \pm 15.6$ & $0.036^{*}$ \\
ESR second hour $(\mathrm{mm} / \mathrm{h})$ & $55.7 \pm 21.9$ & $41.9 \pm 19.1$ & $0.016^{*}$ \\
CRP $(\mathrm{mg} / \mathrm{l})$ & $54.1 \pm 50.4$ & $48.6 \pm 44.2$ & 0.777 \\
Fibrinogen level $(\mathrm{g} / \mathrm{l})$ & $15.5 \pm 7.5$ & $14.2 \pm 8.9$ & 0.530 \\
\hline
\end{tabular}

CRP, C-reactive protein; ESR, erythrocyte sedimentation rate; MPV, mean platelet volume; RBCs, red blood cell count; RDW, red blood cells distribution width; WBCs, white blood cell count. *Significant.

Table 4 Predictors of treatment failure among chronic obstructive pulmonary disease patients

\begin{tabular}{lcccc}
\hline & $P$-value & OR & \multicolumn{2}{c}{$95 \% \mathrm{Cl}$} \\
\cline { 3 - 5 } & & & Lower & Upper \\
\hline $\mathrm{PaCO}_{2}(\mathrm{mmHg})$ & $0.017^{*}$ & 0.818 & 0.694 & 0.965 \\
$\mathrm{PaO}_{2}(\mathrm{mmHg})$ & $0.018^{*}$ & 3.702 & 1.253 & 10.939 \\
ESR first hour $(\mathrm{mm})$ & $0.040^{*}$ & 1.488 & 1.012 & 2.188 \\
RDW\% & 0.307 & 0.883 & 0.697 & 1.120 \\
PEFR (I/min) & 0.098 & 1.024 & 0.996 & 1.053 \\
\hline
\end{tabular}

$\mathrm{Cl}$, confidence interval; ESR, erythrocyte sedimentation rate; OR, odds ratio; $\mathrm{PaCO}_{2}$, partial pressure of $\mathrm{CO}_{2}$ in arterial blood; $\mathrm{PaO}_{2}$, partial pressure of $\mathrm{O}_{2}$ in arterial blood; PEFR, peak expiratory flow rate; RDW, red distribution width; $\mathrm{SaO}_{2}$, oxygen saturation in the arterial blood; *Significant. 
Figure 2

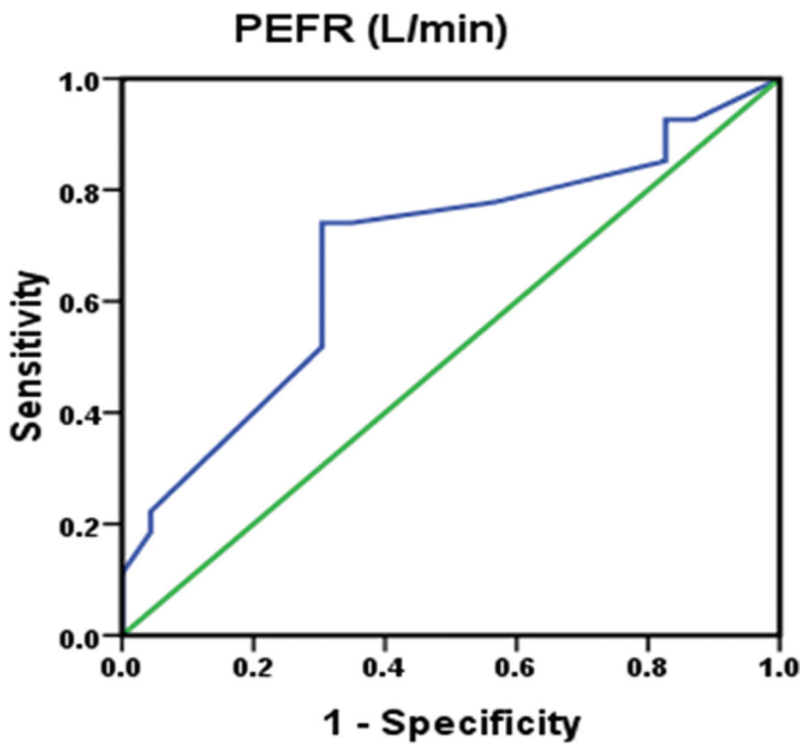

ROC curve of optimal cut-off level of PEFR $\leq 225 \mathrm{~L} / \mathrm{min}$ associated with treatment failure with sensitivity of $74.1 \%$ and specificity of $69.6 \%$.

\section{Figure 3}

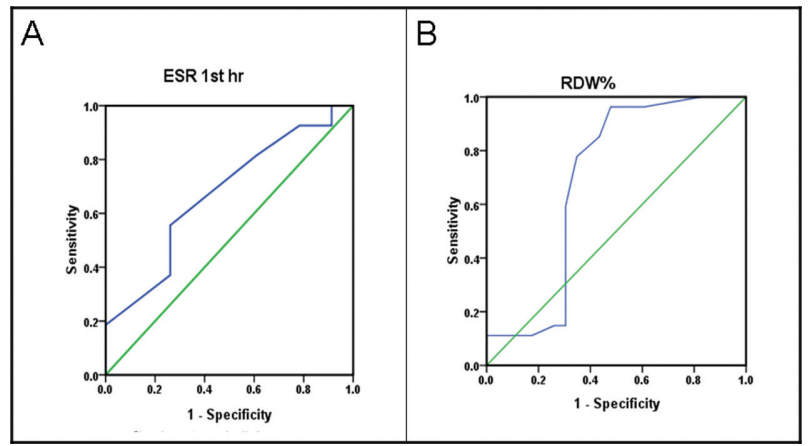

ROC curve of optimal cut-off level of ESR $1^{\text {st }}$ hour $(\geq 35)$ associated with treatment failure with sensitivity of $55.6 \%$ and specificity of $74.9 \%$ (figure A). ROC curve of optimal cut-off level of RDW $\geq 15.5 \%$ associated with treatment failure with sensitivity of $77.8 \%$ and specificity of $65.2 \%$ (figure B).

RDW of at least $15.5 \%$ was associated with the treatment failure with a sensitivity of $77.8 \%$ and specificity of $65.2 \%$ (Fig. 3b).

\section{Discussion}

COPD is a worldwide prevalent disease [16]. Hospitalized patients with COPD exacerbations are at increased risk of morbidity [17] and expenses related to disease management [18]. There are strong data indicating that systemic corticosteroids are highly indicated in COPD exacerbations. However, there are insufficient data about the optimal duration of corticosteroid therapy during AECOPD. Furthermore, the factors predicting treatment failure during hospitalization have not yet been described. That study was carried out to evaluate the outcome of short-term systemic steroid therapy ( $\leq 5$ days) in COPD patients hospitalized with acute exacerbation and to identify the factors associated with treatment failure.

In this study, patients of COPD exacerbations using short-term steroid therapy were evaluated. Patients were assessed clinically, functionally, and by gasometric and laboratory markers at day 1 and 5 after initiation of $40 \mathrm{mg}$ systemic steroids. At day 5, the outcome of treatment was assessed. Treatment failure was found in 27 (54\%) of the patients with AECOPD. This rate of treatment failure was higher than previously observed in studies. Some studies reported treatment failure by $14.5 \%[19,20]$ and others reported [21] a higher rate of failure (about $39 \%)$ in the treated group. That variability in outcome could be related to different grades of COPD stages or their exacerbations and the timing of each study identified the treatment failure.

Clinically, patients were evaluated using a clinical symptom score. Patients with treatment failure were significantly presented with higher cough and chest tightness scores compared with the treatment success group. Paradoxically, Crisafulli and colleagues found that the COPD patients with failed short-term steroid therapy had low prevalence of cough at admission. As cough has an essential role in enhancing mucus clearance, it surely has a beneficial impact on the treatment [22]. It is suggested that not absence of cough, but insufficient cough could account for retention of secretions with vicious circle of secondary infection and more deterioration of the condition [23].

On functional assessment of COPD patients, PEFR was used as a method of monitoring during the followup study period. Emerman et al. [24] have studied the use of peak expiratory flow rate in the emergency department for evaluation of AECOPD and found a good correlation between FEV1 and PEFR. However, Orio et al. [25] have found that there was no statistical difference in the response to ED treatment of AECOPD by measuring PEF between patients successfully treated as outpatients and those who were admitted or failed outpatient treatment. But the later study evaluated PEFR in the assessment of outcome of outpatient treatment in ED and not during the whole exacerbation period. So, we could suggest that PEFR could be used as an option for the evaluation of airway obstruction during an exacerbation period. Owing to being a cheap, easyto-use, and rapid test, PEF can be applied for the monitoring of COPD patients [26]. 
Regarding laboratory parameters, this study observed that RDW was significantly higher in the treatment failure group compared with the success group. RDW was also shown to be significantly increased in patients with acute exacerbation compared with stable COPD subjects [27]. Deformation of red cell membranes is a known entity in inflammation. Due to the presence of systemic inflammation in COPD patients, inflammatory molecules may interact with erythropoiesis in the bone marrow and stimulate the production of red cells in variable sizes [28].

$\mathrm{CRP}$ is also produced by the liver in response to systemic inflammation in COPD exacerbation [29]. Elevated CRP levels are also possibly associated with treatment failure [30] and are independent predictor of prognosis [31] in COPD patients. However, in the present study, no significant differences were observed between the treatment failure group and success group regarding the baseline CRP level. As elevated serum CRP levels are seen with bacterial exacerbation [9], both our groups were presented with bacterial exacerbation, so it could be expected that the two groups were not different. However CRP can be used in monitoring during COPD exacerbation as it is usually elevated at exacerbation and decreased with treatment [32].

The most hopeful blood biomarker in COPD was fibrinogen. Plasma fibrinogen had been variably associated with the risk of COPD progression [33]. The level of plasma fibrinogen was also increased during exacerbations in comparison to stable COPD cases [34]. At day 1 of our study, although the level of fibrinogen is less in the success group than in the failure group, it did not reach significant difference. Its levels needed at least 30 days to return to previous preexacerbation levels $[35,36]$.

\section{Conclusion}

Most patients with severe and very severe COPD presented with acute exacerbations need prolonged course of systemic steroids ( $>5$ days). Clinical parameters, laboratory parameters such as RDW and ESR, PEFR and gasometric parameters could be good predictors of treatment failure on short-term systemic steroids during AECOPD and on the need for a more prolonged course of steroid therapy. Further studies are recommended to assess short-term systemic steroid in mild and moderate COPD patients with acute exacerbation.

\section{Acknowledgements}

Professor Ashraf Zin contributed to the concepts, design of the study, and to the definition of intellectual content. Professor Lamiaa H. Shaaban contributed to the definition of intellectual content, manuscript review, and takes responsibility of the integrity of the work as a whole from inception to published article. Shereen Farghaly contributed to the literature search, clinical studies, data analysis, statistical analysis, manuscript preparation, and to the manuscript review. Hanan Galal contributed to the concepts of the study and definition of intellectual content, manuscript review. Entsar H. Mohammed contributed to data acquisition, data analysis, and statistical analysis.

The authors acknowledges the residents and the nurses for their help during the study.

\section{Financial support and sponsorship \\ Nil.}

\section{Conflicts of interest}

There are no conflicts of interest.

\section{References}

1 Global strategy for the diagnosis, management, and prevention of COPD: Revised 2017. Global initiative for chronic obstructive lung disease (GOLD). Available at: http://www.goldcopd.org. [Accessed 2017].

2 Celli BR, Barnes PJ. Exacerbations of chronic obstructive pulmonary disease. Eur Respir J 2007; 29:1224-1238.

3 Aaron SD, Angel JB, Lunau M, Wright K, Fex C, Le Saux N, et al. Granulocyte inflammatory markers and airway infection during acute exacerbation of chronic obstructive pulmonary disease. Am J Respir Crit Care Med 2001; 163:349-355.

4 Calikoglu M, Sahin G, Unlu A, Ozturk C, Tamer L, Ercan B, et al. Leptin and TNF-alpha levels in patients with chronic obstructive pulmonary disease and their relationship to nutritional parameters. Respiration 2004; 71:45-50.

5 Saetta M, Baraldo S, Zuin R. Neutrophil chemokines in severe exacerbations of chronic obstructive pulmonary disease: fatal chemoattraction. Am J Respir Crit Care Med 2003; 168:911-913.

6 Zhu J, Qiu YS, Majumdar S, Gamble E, Matin D, Turato G, et al. Exacerbations of bronchitis: bronchial eosinophilia and gene expression for interleukin-4, interleukin-5, and eosinophil chemoattractants. Am J Respir Crit Care Med 2001; 164:109-116.

7 Tsoumakidou M, Tzanakis N, Chrysofakis G, Kyriakou D, Siafakas NM. Changes in sputum T-lymphocyte subpopulations at the onset of severe exacerbations of chronic obstructive pulmonary disease. Respir Med 2005; 99:572-579.

8 Jadwiga A, Wedzicha A, Terence A, Paul EA, Donaldson GC, Bhowmik A, et al. Acute exacerbations of chronic obstructive pulmonary disease are accompanied by elevations of plasma fibrinogen and serum IL-6 levels. Thromb Haemost 2000; 84:147-361.

9 Peng C, Tian C, Zhang Y, Yang X, Feng Y, Fan H. C-reactive protein levels predict bacterial exacerbation in patients with chronic obstructive pulmonary disease. Am J Med Sci 2013; 345:190-194.

10 Anthonisen NR, Manfreda J, Warren CP, Hershfield ES, Harding GKM, Nelson NA. Antibiotic therapy in exacerbations of chronic obstructive pulmonary disease. Ann Intern Med 1987; 106:196-204.

11 Leuppi JD, Schuetz P, Bingisser R, Bodmer M, Briel M, Drescher T, et al. Short-term vs. conventional glucocorticoid therapy in acute exacerbations of chronic obstructive pulmonary disease: the REDUCE randomized clinical trial. JAMA 2013; 309:2223-2231.

12 Global Initiative for Obstructive Lung Disease. Global initiative for obstructive lung disease. 2007. Available at: http://www.goldcopd.com. [Accessed 12 July 2007]. 
13 Calverley P, Pauwels R, Lofdah CG, Svensson K, Higenbottam T, Carlsson LG, et al. Relationship between respiratory symptoms and medical treatment in exacerbations of COPD. Eur Respir J 2005; 26:406-413.

14 Lieberman D, Ben-Yaakov M, Lazarovich Z, Lazarovich Z, Hoffman S, Ohana B, et al. Infectious etiologies in acute exacerbation of COPD. Diagn Microbiol Infect Dis 2001; 40:95-102.

15 Chow AW, Hall CB, Klein JO, Kammer RB, Meyer RD, Remington JS. Evaluation of new antiinfective drugs for the treatment of respiratory tract infections. Infectious Diseases Society of America and the Food and Drug Administration. Clin Infect Dis 1992; 15:S62-S88.

16 Buist AS, McBurnie MA, Vollmer WM, Gillespie S, Burney P, Mannino DM, et al. International variation in the prevalence of COPD (the BOLD Study): a population-based prevalence study. Lancet 2007; 370:741-750.

17 Connors AF Jr, Dawson NV, Thomas C, Harrell FE Jr, Desbiens N, Fulkerson WJ, et al. Outcomes following acute exacerbation of severe chronic obstructive lung disease. The SUPPORT investigators (Study to Understand Prognoses and Preferences for Outcomes and Risks of Treatments). Am J Respir Crit Care Med 1996; 154:959-967.

18 Wouters EF. The burden of COPD in the Netherlands: results from the confronting COPD survey. Respir Med 2003; 97:S51-S59.

19 Alia I, de la Cal MA, Esteban A, Abella A, Ferrer R, Molina FJ, et al. Efficacy of corticosteroid therapy in patients with an acute exacerbation of chronic obstructive pulmonary disease receiving ventilatory support. Arch Intern Med 2011; 171:1939-1946.

20 Crisafulli E, Torres A, Huerta A, Guerrero M, Gabarrús A, Gimeno A, et al. Predicting in-hospital treatment failure ( $\leq 7$ days) in patients with COPD exacerbation using antibiotics and systemic steroids. COPD 2016; 13:82-92.

21 Daniels JM, Snijders D, de Graaff CS, Vlaspolder F, Jansen HM, Boersma $W G$, et al. Antibiotics in addition to systemic corticosteroids for acute exacerbations of chronic obstructive pulmonary disease. Am J Respir Crit Care Med 2010; 181:150-157.

22 Smith J, Woodcock A. Cough and its importance in COPD. Int $J$ Chron Obstruct Pulmon Dis 2006; 1:305-314.

23 Smina M, Salam A, Khamiees M, Gada P, Amoateng-Adjepong Y, Manthous C. Cough peak flows and extubation outcomes. Chest 2003; 124:1-6.

24 Emerman CL, Cydulka RK. Use of peak expiratory flow rate in emergency department evaluation of acute exacerbation of chronic. Obstruct Pulmon Dis 1996; 27:159-163.
25 Orio KE, Veesart J, Westermeyer R. The use of peak flow during acute exacerbations of chronic obstructive pulmonary disease in the emergency department. Ann Emerg Med 2004; 44:S36-S37.

26 Perez-Padilla R, Vollmer WM, Vazquez-Garcia JC, Enright PL, Menezes AM, Buist AS, et al. Can a normal peak expiratory flow exclude severe chronic obstructive pulmonary disease?. Int J Tuberc Lung Dis 2009; 13:387-393.

27 Aktas G, Sit M, Dikbas O, Tekce BK, Savli H, Tekce H, et al. Could red cell distribution width be a marker in Hashimoto's thyroiditis?. Exp Clin Endocrinol Diabetes 2014; 122:572-574.

28 Koçak MZ. Evaluation of red cell distribution width levels during acute exacerbation in patients with chronic obstructive pulmonary disease. Biomed Res 2017; 28:3009-3011.

29 Pepys MB, Hirschfield GM. C-reactive protein: a critical update. J Clin Invest 2003; 111:1805-1812.

30 Perera WR, Hurst JR, Wilkinson TM, Sapsford RJ, Müllerova H, Donaldson GC, et al. Inflammatory changes, recovery and recurrence at COPD exacerbation. Eur Respir J 2007; 29:527-534.

31 Dahl $M$, Vestbo J, Lange $P$, Bojesen SE, Tybjærg-Hansen A, Nordestgaard BG. C-reactive protein as a predictor of prognosis in chronic obstructive pulmonary disease. Am J Respir Crit Care Med 2007; 175:250-255.

32 Valipour A, Schreder M, Wolzt M, Saliba S, Kapiotis S, Eickhoff $P$, et al. Circulating vascular endothelial growth factor and systemic inflammatory markers in patients with stable and exacerbated chronic obstructive pulmonary disease. Clin Sci (Lond) 2008; 115:225-232.

33 Duvoix A, Dickens J, Haq I, Mannino D, Miller B, Tal-Singer R, et al. Blood fibrinogen as a biomarker of chronic obstructive pulmonary disease. Thorax 2013; 68:670-676.

34 Thomas BK, Yuvarajan S. Plasma fibrinogen in chronic obstructive pulmonary disease - a cross sectional study conducted in a Tertiary Care Hospital in Puducherry, India. Br J Med Med Res 2016; 14:1-8.

35 Saldias PF, Diaz PO, Dreyse DJ, Gaggero BA, Sandoval AC, Lisboa BC. Etiology and biomarkers of systemic inflammation in mild to moderate COPD exacerbations. Rev Med Chil 2011; 140:10-18.

36 Koutsokera A, Kiropoulos TS, Nikoulis DJ, Daniil ZD, Tsolaki V, Tanou K, et al. Clinical, functional and biochemical changes during recovery from COPD exacerbations. Respir Med 2009; 103:919-926. 